УДК 541.127: 542.943

[0000-0001-9251-5017] О. В. Суворін, д.m.н., професор,

e-mail: avsuvorin@ukr.net

М. М. Шорохов, аспірант кафедри хімічної інженерії та екології, e-mail: teplopribors@i.ua

${ }^{[0000-0003-3862-1964]}$ М. А. Ожередова, к.m.н, доиент

e-mail: ozheredovama@ukr.net

${ }^{[0000-0002-4697-1975]}$ C. І. Зуб̆цов, к. т.н, дочент

e-mail: mining_07@i.ua

Східноукраїнський національний університет імені Володимира Даля

м. Сєвєродонецьк, Україна

\title{
ВИСОКОЕФЕКТИВНА ТЕХНОЛОГІЯ ЗНЕШКОДЖЕННЯ Cr (VI)-ВМІСНИХ ПРОМИВНИХ ВОД ЕЛЕКТРОХІМІЧНИХ ВИРОБНИЦТВ
}

Робота присвячена розробиі технології знешкодження Cr(VI)-вмісних промивних вод електрохімічних виробництв. Як реагент-осаджувач пропонується використовувати водний розчин барій (II) гідроксиду. Експериментально обгрунтовано температуру процесу очищення і надлишок реагенту-осаджувача для отримання залишкової конщентрації Cr (VI) в очищеній воді на рівні значень ГДК та максимальної швидкості розшаровування суспензії.

Ключові слова: стічні води, Cr (VI), реагентне знешкодження, температура, залишкова концентрачія, очищена вода, швидкість розшарування.

Вступ. Серед найважливіших проблем у сфері захисту навколишнього середовища особливе місце займає охорона водного середовища від забруднень, найбільш небезпечними $з$ яких є стічні води, що містять важкі та кольорові метали. Очищення стоків на багатьох підприємствах країни, як правило, є недосконалим, і очищена вода не відповідає вимогам міжнародних стандартів.

Процеси електрохімічного хромування супроводжуються утворенням стічних та промивних вод, що містять сполуки високотоксичного $\mathrm{Cr}^{6+}$. Зростаючі викиди таких забруднень мають розміри серйозної загрози для екосистеми.

Разом з тим у виробничих стічних водах хром має значну цінність, а його вилучення та повторне використання у виробництві може дати значний економічний ефект. Крім того, при повторному використанні очищених вод значно скорочуються витрати на водоспоживання та водовідведення. Однак велика різноманітність складу хромвмісних стічних вод, великі капітальні та експлуатаційні витрати на комплекси водоочищення підприємств галузі створюють труднощі в організації технологічної схеми очищення стічних вод від іонів хрому. Скидання таких вод у поверхневі водні об'єкти, без попереднього очищення до норм ГДК, заборонено.
Нині універсальних прийомів очищення виробничих стоків від хрому не існує. Для очищення стоків використовуються різні методи: реагентні, електро- та гальванокоагуляційні, іонообмінні, електродіалізні, сорбційні, мембранне розділення, біологічні та ін. Кожен із цих методів має свої характерні переваги та недоліки.

Реагентний метод утилізації хромвмісних стічних вод полягає в переведенні іонів хрому (VI) в тривалентний стан і осадженні їх у вигляді нерозчинного продукту. Реагентний метод можна вважати двоступеневим, однак після одержання нерозчинних продуктів пульпа проходить ще декілька етапів обробки: відстоюється і фільтрується через фільтр-прес 3 отриманням осаду [1].

Метод в цілому є порівняно простим у реалізації, не вимагає спеціального обладнання. Він дає змогу працювати у великому діапазоні параметрів стоків (якісний і кількісний склад, $\mathrm{pH}$ тощо), що в умовах реального виробництва вельми зручно. Тому більшість великих машинобудівних заводів використовують саме цей метод очищення стічних вод.

Проте наявні недоліки реагентного методу суттєво знижують його ефективність. Так, осади, що утворюються, відзначаються не тільки складним складом, але й аморфною гелевою структурою [2]. У такому вигляді їх фільтрація та сушіння становлять істотну тех-

(C) О. В. Суворін, М. М. Шорохов, М. А. Ожередова, С. І. Зубцов, 2019 DOI: $10.24025 / 2306-4412.4 .2019 .185446$ 
нічну й економічну проблему для підприємств.

Однак, незважаючи на перелічені недоліки, реагентний метод знешкодження стічних вод, що містять хром (VI), не втратив своєї актуальності. Так, наприклад, якщо як осаджувач використовувати водні розчини сполук $\mathrm{Ba}^{2+}\left(\mathrm{Ba}(\mathrm{OH})_{2}, \mathrm{BaCl}_{2}, \mathrm{Ba}\left(\mathrm{NO}_{3}\right)_{2}\right.$ та інші водорозчинні сполуки) або сполук $\mathrm{Pb}^{2+}$ $\left(\mathrm{Pb}\left(\mathrm{CH}_{3} \mathrm{COO}\right)_{2}, \mathrm{PbCl}_{2}, \mathrm{~Pb}\left(\mathrm{NO}_{3}\right)_{2}\right.$ та ін. $)$, то в результаті реакцій отримаємо важкорозчинні хромати барію або свинцю [3].

Іонообмінні методи очищення дають можливість проводити очищення відпрацьованих розчинів від іонів хрому (III) та хрому (VI), дають можливість вести обробку великих об'ємів розчинів (до сотень м $^{3} /$ год.), вимагають порівняно невеликої витрати електроенергії, є можливість повної автоматизації процесу. У той же час іонообмінні методи мають істотні недоліки: вимагають попередньої реагентної обробки відпрацьованих розчинів 3 метою поділу змішаних стоків і потребують значних витрат на придбання іонітів. Існує також проблема елюатів, які мають бути додатково перероблені в утилізовані речовини. Без вирішення проблеми утилізації елюатів іонообмінне очищення призводить до збільшення майже в три рази сумарної кількості сольових скидів [2].

3 метою запобігання утворенню змішаних осадів застосовують сорбційне очищення відпрацьованих розчинів від іонів хрому. Сорбційні методи $€$ високоефективними i найбільш екологічно чистими. Основними параметрами вибору матеріалу для використання цього методу є сорбційні якості, пористість та економічність. Як сорбенти для знешкодження відпрацьованих хромвмісних розчинів знаходять використання вуглецеві сорбенти $[4,5,6]$, сполуки заліза [7], різні природні біоматеріали.

До переваг адсорбційного методу слід віднести: очищення до вимог ГДК; можливість рекуперації речовин, що сорбуються; після коригування $\mathrm{pH} є$ можливість повернення очищеної води у виробництво. Однак метод не позбавлений і недоліків, до яких можна віднести: невисоку продуктивність сорбційних установок; природні сорбенти застосовні для обмеженого кола домішок та їх концентрацій; громіздкість устаткування; обмеження роботи матеріалів за областями $\mathrm{pH}$ вихідної води; складність регенерації [8].
Електрохімічні методи нейтралізації або регенерації хромвмісних стоків поділяються на: електроліз без діафрагми і мембранний електроліз з однією або декількома мембранами; електрокоагуляцію і гальванокоагуляцію; електрофлокуляцію; електрофлотацію [2].

Суть електрохімічних методів, в яких хром бере участь у реакціях на електродах, полягає, в першу чергу, в деактивації шестивалентного хрому шляхом відновлення його на катоді до тривалентного стану. Для того щоб на аноді не відбувалося зворотної реакції окиснення, можуть застосовуватися мембрани і діафрагми.

Перевагами електролітичного методу відновлення хрому (зокрема, із застосуванням діафрагм) $є$ швидкість і повнота відновлення. Однак процес вимагає точного дотримання параметрів стоків, що надходять на очищення, чого в реальних виробничих умовах домогтися дуже складно. Крім цього, до складу стоків можуть входити сторонні іони, які заважають процесу відновлення. Осадів під час електролізу не утворюється. Незважаючи на всі переваги, електрохімічне відновлення нечасто застосовується у реальних гальванічних виробництвах через складність обладнання і загальну дорожнечу процесу.

Електро- і гальванокоагуляційний методи використовуються, в основному, для очищення хромвмісних стоків від іонів $\mathrm{Cr}(\mathrm{VI})$. В обох методах спочатку проводять розчинення заліза, далі іони $\mathrm{Fe}^{2+}$, що утворилися, відновлюють $\mathrm{Cr}^{6+}$ до $\mathrm{Cr}^{3+}$ з подальшим утворенням $\mathrm{Cr}(\mathrm{OH})_{3}$. Окрім залізних анодів, можливо використовувати й алюмінієві $[9,10]$.

Відмінність методів полягає у різній рушійній силі процесу розчинення металевого заліза, що і визначає особливості застосування електро- та гальванокоагуляційних апаратів [11].

Так, при експлуатації електрокоагуляторів спостерігається засмічення міжелектродного простору, що викликає необхідність у постійному прочищенні його скребками. При обслуговуванні гальванокоагуляторів необхідно постійно підтримувати співвідношення сталевої стружки і коксу або сталевої і мідної стружки. Також $є$ незручності завантаження апарату та необхідність ретельної фільтрації розчину, що очищається, від дрібнодисперсної фази, яка містить оксиди заліза і частинки коксу [12].

(C) О. В. Суворін, М. М. Шорохов, М. А. Ожередова, С. І. Зубцов, 2019 DOI: $10.24025 / 2306-4412.4 .2019 .185446$ 
Недоліками методів є використання великої кількості кислоти і лугу та утворення значної кількості осаду, який практично не утилізується. Він являє собою суміш гідроксидів заліза і хрому, в перерахунку на суху вагу - близько 10 кг на 1 кг хрому (III), що міститься у вихідному розчині [13].

В цілому слід зазначити, що всі електрохімічні методи досить дорогі в експлуатації, вимагають дорогого устаткування, кваліфікованого обслуговуючого персоналу і високої культури виробництва. Вузький діапазон концентрацій забруднених стоків не дозволяє використовувати ці методи як універсальні для очищення хромвмісних стічних вод, відводячи їм роль лише для доочищення стоків.

Мембранні методи добре підходять для очищення низькоконцентрованих відпрацьованих розчинів, оскільки стоки високої концентрації дуже швидко виводять мембрани 3 ладу, причому якість очищення в цьому випадку виявляється невисокою. У реальних умовах, також як і при електрохімічних методах очищення, підтримувати точно задані параметри стоків складно. Мембранні методи добре виправдовують себе для регенерації компонентів відпрацьованих розчинів та деяких видів промивних вод після технологічних операцій. Однак ці методи є досить дорогими в експлуатації.

Мембранні технології використовують два типи мембран - напівпроникні мембрани, радіус пор яких менший, ніж радіус забруднюючих іонів або молекул, та іонообмінні, які спроможні пропускати іони певного знака [2].

Серед мембранних методів виділяють: мікрофільтрацію, ультрафільтрацію, нанофільтрацію, зворотний осмос, діаліз, електродіаліз, випаровування через мембрани [14]. Найбільшої ефективності й технологічності щодо виділення важких металів, зокрема хрому, дають змогу досягти наступні методи: зворотний осмос (гіперфільтрація), ультрафільтрація та електродіаліз.

Найбільшого поширення для очищення стічних вод від іонів хрому набули три основні типи матеріалів мембран: різновиди ацетату целюлози, поліамідний полімер і складні композиційні мембрани, які являють собою тонкі плівки поліаміду, що накладаються на пористі полімерні субстрати, наприклад полісульфон, полівенілфторид $[15,16,17]$.

Ефективність очищення стічних вод від хрому зворотним осмосом та ультрафільтра- цією становить 94-95 \%. Окрім цього, є можливість здійснювати очищення від комплексних іонів та створити зворотний цикл по воді (майже $60 \%$ очищеної води можливо повернути у виробництво).

До недоліків методів можна віднести:

- відпрацьовані розчини потребують попередньої фільтрації,

- мембрани є досить дефіцитними, чутливими до зміни технологічних характеристик відпрацьованих розчинів, що подаються на очищення, та мають значну вартість,

- $\epsilon$ складнощі в експлуатації обладнання та висуваються високі вимоги до його герметичності [13].

Біологічні методи очищення знаходять все більш широке застосування завдяки таким важливим факторам, як низька витрата енергії, відсутність вторинного забруднення води, відносно невисокі експлуатаційні витрати, здатність забезпечувати жорсткі нормативи умов скидання [18].

Біологічний метод є альтернативою використанню хімічних реагентів. В його основі лежить самоочищення водойм і здатність рослин і мікроорганізмів накопичувати важкі метали.

Висока аккумулятивна здатність мікроводоростей відносно важких металів створює перспективи їх використання при очищенні стічних вод. Існуючий досвід у біотехнології показує, що ефективність акумулювання досягає $95 \%$ [19].

До бактерій, що здатні відновлювати $\mathrm{Cr}^{6+}$ до $\mathrm{Cr}^{3+}$, відносяться бактерії родів Pseudomonas, Aeromonas i Escherichia. Вони здатні переносити концентрацію іонів $\mathrm{Cr}^{6+}$ вище 200 мг/л, при цьому час відновлення становить 1-3 доби, який зростає до 20 і 60 діб при збільшенні початкової концентрації сполук хрому відповідно до 350 і 500 мг/л [20].

Загальними недоліками біологічних методів знешкодження відпрацьованих розчинів від іонів хрому (VI) є чутливість мікроорганізмів до зміни складу стічних вод і підвищення концентрації токсичних компонентів; значні займані площі; недостатній ефект очищення; тривалість технологічного процесу. Також після очищення всередині біомаси накопичується хром, який далі знову потрібно утилізувати, вже в формі біоматеріалу.

Таким чином, утилізацію відпрацьованих хромвмісних розчинів можна здійснювати багатьма способами. Одним із найбільш прий-

(C) О. В. Суворін, М. М. Шорохов, М. А. Ожередова, С. І. Зубцов, 2019 DOI: $10.24025 / 2306-4412.4 .2019 .185446$ 
нятних слід вважати реагентний метод. В роботі [11] показано, що реагентний метод знешкодження стічних вод, що містять $\mathrm{Cr}(\mathrm{VI})$, незважаючи на такі явні недоліки, як необхідність використання товарних реактивів та складність досягнення залишкової концентрації $\mathrm{Cr}^{6+}$ на рівні нормативів ГДК, не втратив своєї актуальності.

На підставі проведених нами попередніх досліджень запропонований як осаджувач водний розчин барій (II) гідроксиду (баритова вода) [3]. Однак малодослідженими $є$ питання впливу температури і надлишку осаджувача на властивості одержуваної суспензії і залишкову концентрацію $\mathrm{Cr}^{6+}$ в очищених розчинах.

Метою роботи $\epsilon$ визначення оптимального температурного режиму та надлишку осаджувача в рамках розробки технології знешкодження $\mathrm{Cr}(\mathrm{VI})$-вмісних промивних вод електрохімічних виробництв.

Методика експерименту. У термостатований циліндричний реактор заливався розчин $\mathrm{H}_{2} \mathrm{CrO}_{4} 3$ концентрацією 90 мг/л, який моделює типові промивні води після операції промивання виробів, підданих електрохімічному хромуванню. Після досягнення заданої температури, яку підтримували на рівні 20 , $30,40,50$ і $60{ }^{\circ} \mathrm{C}$ (точність регулювання $\left.\pm 0,5{ }^{\circ} \mathrm{C}\right)$, в реактор при перемішуванні зі швидкістю $\approx 2$ об/с дозували насичений при $20{ }^{\circ} \mathrm{C}$ водний розчин $\mathrm{Ba}(\mathrm{OH})_{2}$, попередньо нагрітий до температури експерименту. Дозування розчину здійснювали після попереднього розрахунку, виходячи з отримання осаду барій (II) хромату за нерівноважною реакцією

$$
\mathrm{H}_{2} \mathrm{CrO}_{4}+\mathrm{Ba}(\mathrm{OH})_{2} \rightarrow \mathrm{BaCrO}_{4}+\mathrm{H}_{2} \mathrm{O},
$$

виходячи 3 мольного співвідношення $A=\frac{B a^{2+}}{C r^{6-}}=1,0 ; 1,2 ; 1,3 ; 1,4 ; 1,5 ; 1,7$ і $2,0$. Кожну з суспензій витримували при заданій температурі і перемішуванні протягом 30 хв, після чого перемішування зупиняли, і в умовах природного охолодження відбувалося розшарування суспензії, яка утворилася. В освітленій частині суспензії визначали залишкову концентрацію $\mathrm{Cr}$ (VI) і pH середовища.

Для визначення вмісту іонів $\mathrm{Cr}^{6+}$ використовувалися відомі титриметричні методики [21], для визначення малих концентрацій спектрофотометр DR 1900 і методичні рекомендації до нього.
$\mathrm{pH}$ середовища визначали за допомогою приладу Eutech CyberScan pH-метр $700 \mathrm{pH} / \mathrm{mV}$, забезпеченого $\mathrm{pH}$-електродом ECFC7252101B.

Швидкість розшарування суспензій визначали за методикою, запропонованою в [22].

Для приготування робочих розчинів використовували хромовий ангідрид кваліфікації «Ч» за ГОСТ 3776-78 і барій (II) гідроокис кваліфікації «Ч» за ГОСТ 4107-78.

Результати та їх обговорення. Результати впливу мольного співвідношення $A$ на ступінь очищення розчину від $\mathrm{Cr}^{6+}$ зображено на рисунку 1.

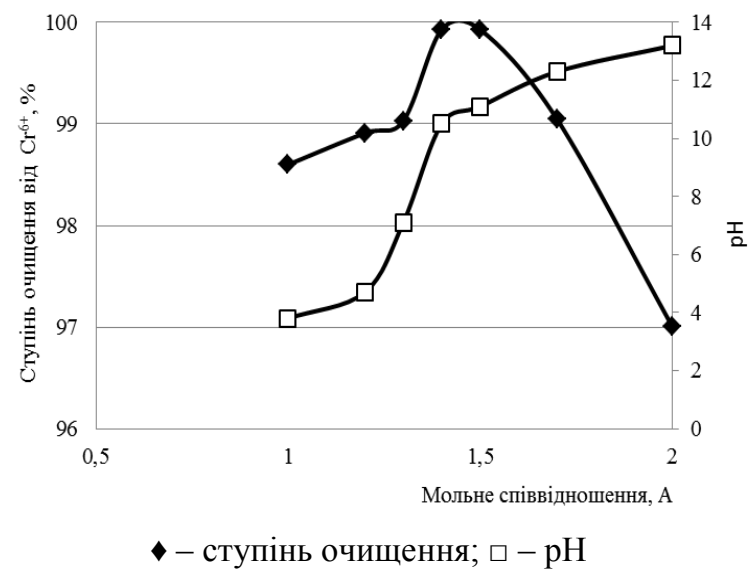

Рисунок 1 - Вплив співвідношення $\boldsymbol{A}$ на ступінь очищення розчину від $\mathrm{Cr}^{6+}$ при $\mathrm{T}=20^{\circ} \mathrm{C}$

Дані, зображені на рисунку 1, показують, що найбільший ступінь очищення $99,93 \%$ досягається при $A=1,4 \div 1,5$. Екстремальний характер кривої пояснюється тим, що збільшення співвідношення $A$ від 1 до $1,4 \div 1,5$ призводить до збільшення концентрації іонів $\mathrm{Ba}^{2+}$ в розчині і пропорційного зниження концентрації іонів $\mathrm{Cr}^{6+}$ відповідно до закону добутка розчинності $\left[\mathrm{Ba}^{2+}\right] \cdot\left[\mathrm{CrO}_{4}^{2-}\right]=Д \mathrm{BaCrO}_{4}$. Подальше збільшення співвідношення $A$ призводить до збільшення іонної сили розчину, що призводить до зв'язування аніона в комплекс ізополікислоти $\left\{\mathrm{H}_{2}\left[\mathrm{CrO}_{4}\left(\mathrm{CrO}_{3}\right)\right]\right\}$, до утворення якої має велику схильність хром [23].

Результати дослідження впливу температури на залишкову концентрацію хрому та швидкість розшарування суспензії зображено на рисунку 2. 


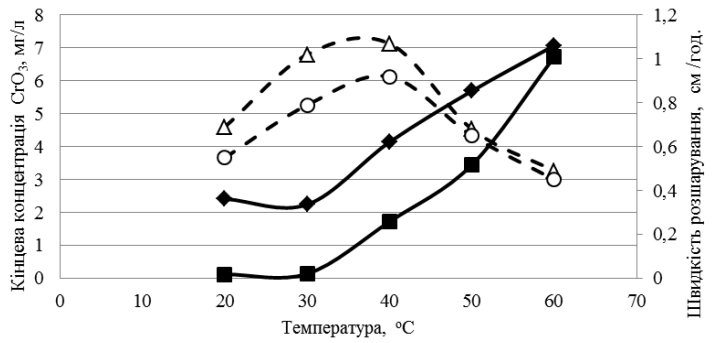

Рисунок 2 - Вплив температури на залишкову концентрацію $\mathrm{CrO}_{3}$ і швидкість розшарування суспензій $C_{C_{r} O_{3}}$ при $A=-1 ; \square-\mathbf{1 , 4}$.

Швидкість розшарування при $A=\circ-1 ; \Delta-1,4$

Аналіз наведених даних показує, що найменші залишкові концентрації $\mathrm{CrO}_{3}$ в розчині ( $\approx 0,12$ мг/л) отримані при температурі $20 \div 30{ }^{\circ} \mathrm{C}$. Найбільша швидкість розшарування суспензій $1,02 \div 1,07 \quad(A=1,4)$ і $0,79 \div 0,92$ $(A=1)$ см/год. досягається при $\mathrm{T}=30 \div 40{ }^{\circ} \mathrm{C}$.

Висновки. Показано, що при реагентному очищенні розчинів від $\mathrm{Cr}^{6+} 3$ використанням як реагенту-осаджувача водного розчину $\mathrm{Ba}(\mathrm{OH})_{2}$ найменші значення залишкових концентрацій $\mathrm{CrO}_{3}$ в очищеному розчині, близькі до значень ГДК для поверхневих водойм, отримані при температурі $20 \div 30{ }^{\circ} \mathrm{C}$ i надлишку осаджувача $40 \div 50 \%$ від стехіометрично необхідної кількості для отримання важкорозчинної солі $\mathrm{BaCrO}_{4}$. 3 урахуванням того, що найбільші швидкості розшарування суспензій спостерігаються в інтервалі температур $30 \div 50{ }^{\circ} \mathrm{C}$, найбільш оптимальним режимом проведення процесу очищення розчинів від сполук $\mathrm{Cr}^{6+}$ слід вважати температуру $25 \div 35^{\circ} \mathrm{C}$ і надлишок осаджувача $40 \div 50 \%$.

\section{Список літератури}

[1] Ю. П. Перелыгин, О.В.Зорькина, И. В. Рашевская и др., Реагентная очистка сточных вод и утилизачия отработанных растворов и осадков гальванических производств: учеб. пособ. Пенза: Изд-во ПГУ, 2013.

[2] С. С. Виноградов, Экологически безопасное гальваническое производство; под ред. проф. В. Н. Кудрявцева; 2-е изд., перераб. и доп. Москва: Глобус, 2002.

[3] М. М. Шорохов, М. А. Ожередова, та О. В. Суворін, "Вплив типу осаджувача на ефективність очищення $\mathrm{Cr}^{6+}$-вмісних стічних вод промислових підприємств", Pers- pectives of science and education: Proc. 3rd Int. Youth Conf. SLOVOIWORD, New York, USA, 2018, pp. 235-244.

[4] R. A.Khaydarov, R. R. Khaydarov, and O. O. Gapurova, "Water purification from metal ion using carbon nanoparticleconjugated polymer nanocomposites", Water Research, vol.44, no. 6, pp. 1927-1933, 2010.

[5] M. Vukĉević et al., "Carbon materials from waste shot hemp fibers as a sorbent for heavy metal ions - Mathematical modeling of sorbent structure and ions transport", Chemscal Engineering Journal, vol. 235, no. 1, pp. 284-292, 2014.

[6] C. Jung et al., "Hexavalent chromium removal by various adsorbents: Powdered activated carbon, chitosan, and single/multiwalled carbon", Separation and Purification Technology, vol. 106, pp. 63-71, 2013.

[7] А. М. Сарсенов, А. К.Казбекова, Н. А. Усенова, и У. А. Есенгулов, "Очистка сточных вод от ионов хрома (III) на фосфате железа (III)", Геология, география и глобальная энергия, № 4, с. 97-101, 2010.

[8] К. Л. Тимофеев, и Л. Ф. Акулич, "Сорбционное извлечение тяжелых металлов из техногенных стоков", Водоочистка. Водоподготовка. Водоснабжение, № 11, c. 26-30, 2012.

[9] E. Bazrafshan, H. Mahvi, S. Naseri, and A. Mesdaghinia, "Performance evaluation of electrocoagulation process for removal of chromium (VI) from synthetic chromium solutions using iron and aluminum electrodes", Turk. J. Eng. Environ. Sci., vol. 32, pp. 5966, 2008.

[10] S. Hamdan, and M. H. El-Naas, "Characterization of the removal of Chromium (VI) from groundwater by electrocoagulation", Journal of Industrial and Engineering Chemistry, vol. 20, pp. 2775-2781, 2014.

[11] С. С. Виноградов, и С. С. Кругликов, "О положительных и отрицательных сторонах электро- и гальванокоагуляционных методов очистки сточных вод", Гальванотехника и обработка поверхности, т. 16, № 1, c. 46-47, 2008.

[12] M. S. Bhatti, A. S. Reddy, and A. K. Thukral "Electrocoagulation removal of $\mathrm{Cr}$ (VI) from simulated wastewater using response surface methodology", Hazard. Mater, vol. 172, pp. 839-846, 2009. 
[13] Ю. П. Хранилов, Экология и гальванотехника: проблемы и решения. Киров: ВятГТУ, 2000.

[14] А. Ю. Токарь, "Мембранные процессы разделения", Международный научноисследовательский журнал, № 1, с. 94-96, 2014.

[15] K. Kolomaznik, M. Barinova, and H. Vaskova, "Chromium VI issue in leather waste", International Journal of Mathematics and Computers in Simulation, vol. 6, no. 5, pp. 447-455, 2012.

[16] P. Kocurek, K. Kolomazník, and M. Bařinová, "Chromium removal from wastewater by reverse osmosis", Wseas transactions on environment and development, vol. 10, pp. 358-365, 2014.

[17] Z. Kaili, W. Xiuju, Zhun, Lu Xingjie, W. Zhongpeng, and W. Liguo, "Preparation and characterization of modified polyvinylidene fluoride/2-amino-4-thiazoleacetic acid ultrafiltration membrane for purification of $\mathrm{Cr}(\mathrm{VI})$ in water", Journal of chemical engineering of Japan, vol. 51, pp. 501-506, 2018.

[18] Д. А. Кривошеин, П. П. Кукин, и В. Л. Лапин, Инженерная защчита поверхностных вод от промышиенных стоков. Москва: Высшая школа, 2003.

[19] Г. О. Горшкова, Т. В. Гудзенко, В. О. Іваниця, та О. В. Волювач, "Спосіб очищення води від хрому (VI) за присутністю мікроорганізмів", ScienceRise: sci. journ., № 9, с. 57-60, 2015.

[20] Б. Н. Ласкорин, Б. В. Громов, А. П. Цыганков, и В. Н. Сенин, Проблемы развития безотходных производств. Москва: Стройиздат, 2005.

[21] Н. Ф. Клещев, Т. Д. Костыркина, Г. С. Бескова, и Е. Т. Моргунова, Аналитический контроль в основной химической промышиленности. Москва: Химия, 1992.

[22] Е. Д. Щукин, А. В. Перцов, и Е. А. Амелина, Коллоидная химия. Москва: Высшая школа, 2004.

[23] Chromium (VI) handbook / [written by Independent Environmental Technical Evaluation Group (IETEG)]; James A. Jacobs, Jacques Guertin, Cynthia Avakian, Eds. CRC Press, 2005.

\section{References}

[1] Yu. P. Perelygin, O. V. Zorkina, I. V. Rashevskaya, et al., Reagent wastewater treatment and disposal of waste solutions and sediments of galvanic production: textbook. Penza: Izd-vo PGU, 2013 [in Russian].

[2] S. S. Vinogradov, Environmentally friendly galvanic production, prof. V. N. Kudryavceva, Ed., 2nd ed. Moscow: Globus, 2002 [in Russian].

[3] M. M. Shorohov, M. A. Ozheredova, and O. V. Suvorin, "Influence of the type of precipitator on the efficiency of purification of $\mathrm{Cr}^{6+}$-contaminated wastewater of industrial enterprises", Perspectives of science and education: Proc. 3rd Int. Youth Conf. SLOVOIWORD, New York, USA, 2018, pp. 235-244 [in Ukrainian].

[4] R. A. Khaydarov, R. R. Khaydarov, and O. O. Gapurova, "Water purification from metal ion using carbon nanoparticleconjugated polymer nanocomposites", Water Research, vol.44, no. 6, pp. 1927-1933, 2010.

[5] M. Vukĉević et al., "Carbon materials from waste shot hemp fibers as a sorbent for heavy metal ions - Mathematical modeling of sorbent structure and ions transport", Chemscal Engineering Journal, vol. 235, no. 1, pp. 284-292, 2014.

[6] C. Jung et al., "Hexavalent chromium removal by various adsorbents: Powdered activated carbon, chitosan, and single/multiwalled carbon", Separation and Purification Technology, vol. 106, pp. 63-71, 2013.

[7] A. M. Sarsenov, A. K. Kazbekova, N. A. Usenova, and U. A. Esengulov, "Wastewater treatment of chromium (III) ions on iron (III) phosphate", Geologiya, geografiya $i$ globalnaya energiya, no. 4, pp. 97-101, 2010 [in Russian].

[8] K. L. Timofeev, and L. F. Akulich, "Sorption extraction of heavy metals from industrial wastes", Vodoochistka. Vodopodgotovka. Vodosnabzhenie, no. 11, pp. 26-30, 2012 [in Russian].

[9] E. Bazrafshan, H. Mahvi, S. Naseri, and A. Mesdaghinia, "Performance evaluation of electrocoagulation process for removal of chromium (VI) from synthetic chromium solutions using iron and aluminum electrodes", Turk. J. Eng. Environ. Sci., vol. 32, pp. 5966, 2008.

[10] S. Hamdan, and M. H. El-Naas, "Characterization of the removal of Chromium (VI) from groundwater by electrocoagulation", 
Journal of Industrial and Engineering Chemistry, vol. 20, pp. 2775-2781, 2014.

[11] S. S. Vinogradov, and S. S. Kruglikov, "On the positive and negative aspects of electroand galvanocoagulation methods of wastewater treatment", Galvanotehnika $i$ obrabotka poverhnosti, vol. 16, no. 1, pp. 46-47, 2008 [in Russian].

[12] M. S. Bhatti, A. S. Reddy, and A. K. Thukral, "Electrocoagulation removal of $\mathrm{Cr}(\mathrm{VI})$ from simulated wastewater using response surface methodology", Hazard. Mater, vol. 172, pp. 839-846, 2009.

[13] Yu. P. Hranilov, Ecology and electroplating: problems and solutions. Kirov: VyatGTU, 2000 [in Russian].

[14] A. Yu. Tokar, "Membrane separation processes", Mezhdunarodnyj nauchnoissledovatelskij zhurnal, no. 1, pp.94-96, 2014 [in Russian].

[15] K. Kolomaznik, M. Barinova, and H. Vaskova, "Chromium VI issue in leather waste", International Journal of Mathematics and Computers in Simulation, vol. 6, no. 5, pp. 447-455, 2012.

[16] P. Kocurek, K. Kolomazník, and M. Bařinová, "Chromium removal from wastewater by reverse osmosis", Wseas transactions on environment and development, vol. 10, pp. 358-365, 2014.

[17] Z. Kaili, W. Xiuju, Zhun, Lu Xingjie, W. Zhongpeng, and W. Liguo, "Preparation and characterization of modified polyvinylidene fluoride/2-amino-4-thiazoleacetic acid ultrafiltration membrane for purification of $\mathrm{Cr}(\mathrm{VI})$ in water", Journal of chemical engineering of Japan, vol. 51, pp. 501-506, 2018.

[18] D. A. Krivoshein, P. P. Kukin, and V. L. Lapin, Engineering protection of surface waters from industrial effluents. Moscow: Vysshaya shkola, 2003 [in Russian].

[19] G. O. Gorshkova, T. V. Gudzenko, V. O. Ivanicya, and $\mathrm{O}$. V. Volyuvach, "A method of purifying water from chromium (VI) in the presence of microorganisms", ScienceRise: sci. journ., no. 9, pp. 57-60, 2015 [in Ukrainian].

[20] B. N. Laskorin, B. V. Gromov, A. P. Cygankov, and V.N. Senin, Problems of development of non-waste production. Moscow: Strojizdat, 2005 [in Russian].

[21] N. F. Kleshev, T. D. Kostyrkina, G. S. Beskova, and E. T. Morgunova, Analytical control in the main chemical industry. Moscow: Himiya, 1992 [in Russian].

[22] E. D. Shukin, A. V. Percov, and E. A. Amelina, Colloid chemistry. Moscow: Vysshaya shkola, 2004 [in Russian].

[23] Chromium (VI) handbook / [written by Independent Environmental Technical Evaluation Group (IETEG)]; James A. Jacobs, Jacques Guertin, Cynthia Avakian, Eds. CRC Press, 2005.

A. V. Suvorin, D. Tech. Sc., professor, e-mail: avsuvorin@ukr.net

M. N. Shorokhov, post-graduate student of the Department of Chemical Engineering and Ecology, e-mail: teplopribors@i.ua

M. A. Ozheredova, $P$ h. D., associate professor, e-mail: ozheredovama@ukr.net

E. I. Zubtsov, Ph. D., associate professor e-mail: mining_07@i.ua

Volodymyr Dahl East Ukrainian National University Severodonetsk, Ukraine

\section{HIGH-EFFECTIVE TECHNOLOGY FOR THE NEUTRALIZATION OF Cr (VI)-CONTAINING WASHWATER OF ELECTROCHEMICAL PLANTS}

The protection of aquatic environment from pollutions, the most dangerous of which is wastewater containing heavy and non-ferrous metals is one of the most important environmental issues.

The processes of electrochemical chromium plating are accompanied by the formation of sewage and washwater containing compounds of highly toxic $\mathrm{Cr}^{6+}$.

However, chromium is of great value in industrial wastewater, and its extraction and reuse in manufacturing can have a significant economic impact. 
The discharge of such water into surface water bodies without prior purification to the maximum permissible concentrations is prohibited.

At present, there are no universal methods of cleaning industrial wastewater from chromium. Various methods, such as: reagent, electro- and galvano-coagulation, ion-exchange, electrodialysis, sorption, membrane separation, biological ones, etc. are used for wastewater treatment. Each of these methods has its own advantages and disadvantages. The analysis of existing methods for the neutralization of chrome-containing spent solutions is described.

The work is devoted to the development of technology for the neutralization of $\mathrm{Cr}$ (VI)containing washwater of electrochemical plants. Aqueous solution of barium (II) hydroxide as a precipitating reagent is proposed to be used. The temperature of the purification process and the excess reagent-precipitator to obtain a residual concentration of $\mathrm{Cr}(\mathrm{VI})$ in purified water at the level of MPC and the maximum rate of delamination of the suspension are experimentally substantiated.

Considering that the highest rates of suspension separation are observed in the temperature range $30 \div 50{ }^{\circ} \mathrm{C}$, the temperature $25 \div 35^{\circ} \mathrm{C}$ and the excess of precipitant $40 \div 50 \%$ should be considered the most optimal regime for the process of purification of solutions from $\mathrm{Cr}^{6+}$ compounds.

Keywords: wastewater, $\mathrm{Cr}(\mathrm{VI})$, reagent neutralization, temperature, residual concentration, purified water, rate of separation

Стаття надійшла 10.11.2019

Прийнято 30.11 .2019 